\title{
Physico-chemical stability and in vitro digestibility of beta-carotene- loaded lipid nanoparticles of cupuacu butter (Theobroma grandiflorum) produced by the phase inversion temperature (PIT) method
}

\author{
Graziela V.L. Gomes a , Mirella R. Sola a , Luís F.P. Marostegan a , Camila G. Jange a , \\ Camila P.S. Cazado ${ }^{a}$, Ana C. Pinheiro ${ }^{\text {b }}$, António A. Vicente ${ }^{b}$, Samantha C. Pinho ${ }^{\text {a, * }}$ \\ a Department of Food Engineering, School of Animal Science and Food Engineering, University of São Paulo (USP), Pirassununga, SP, Brazil \\ ${ }^{\mathrm{b}}$ CEB, Centre of Biological Engineering, University of Minho, Campus de Gualtar, 4710-057, Braga, Portugal
}

\section{A R T I C L E I N F O}

\section{Article history:}

Received 25 April 2016

Received in revised form

2 August 2016

Accepted 7 August 2016

Available online 8 August 2016

\section{Keywords:}

Lipid nanoparticles

Beta-carotene

Nanoencapsulation

In vitro digestion

\begin{abstract}
A B S T R A C T
Beta-carotene is a carotenoid with a wide spectrum of biological activities (e.g., anti-cancer, anti-hypertensive, and anti-inflammatory). However, because of its extremely high hydrophobicity, it is difficult to incorporate in food formulations and its bioavailability is fairly low. Lipid-based encapsulation colloidal systems such as lipid nanoparticles can help overcome these issues. In this study, beta-caroteneloaded lipid nanoparticles were produced by the phase inversion temperature (PIT) method from $10 \%$ cupuacu butter and 20\% surfactant (Cremophor RH40 and Span 80). The inversion temperature of the nanoparticles was $74{ }^{\circ} \mathrm{C}$ and their average diameter was $35 \mathrm{~nm}$. After 100 days of storage, $85 \%$ of the initial amount of beta-carotene remained in the nanoparticles; alpha-tocopherol was found to be essential for carotenoid preservation. Comparison of the results of in vitro digestion between static and dynamic systems was performed, and the characteristics of each digestion system led to diverse results in terms of average particle size and beta-carotene bioaccessibility. Although the static system was much simpler than the dynamic system, it could not provide reliable data of the digestibility of the lipid nanoparticles. The bioaccessibility of beta-carotene in the static system was $92 \%$, very similar to the results found in the literature; by comparison, the dynamic system revealed a beta-carotene bioaccessibility of nearly 20\%. Despite this discrepancy, the highly realistic conditions of digestion simulated by the dynamic in vitro system indicate that the results of this system are more reliable than those obtained from the simplified static system applied in this research.
\end{abstract}

(c) 2016 Elsevier Ltd. All rights reserved.

\section{Introduction}

Incorporation of antioxidant bioactives into food products has developed into a major field in the food industry. Carotenoids are among the most promising antioxidant bioactives that can be incorporated into food; however, these compounds are prone to degradation during storage and processing (Dias et al., 2015). They are also lipophilic, which reduces their bioaccessibility (Porter et al., 2007) and restricts their incorporation into water-based matrices. These drawbacks may be overcome by designing lipid-based waterdispersible microencapsulation systems. Nanoemulsions, which present high physico-chemical stability during storage and a

\footnotetext{
* Corresponding author.

E-mail address: samantha@usp.br (S.C. Pinho).
}

translucent or even transparent appearance because of their very small emulsion droplets (smaller than $100 \mathrm{~nm}$ ) (Izquierdo et al., 2004), are an example of such systems. When nanoemulsions are produced with lipids that are in the solid state at room temperature, they are called solid lipid nanoparticles (Müller et al., 2000). By controlling the physical state of the lipid matrix, control of the mobility of bioactives within these structures may be achieved (Mehnert and Mäder, 2001) and minimization or prevention of some problems such as bioactive expulsion, low bioactive loading, and physical instability (Müller et al., 2002; Wissing et al., 2004) may be possible. The use of lipid mixtures to form nanoparticle cores allows the formation of imperfect crystals, amorphous lipid cores and can minimize or avoid expulsion of the bioactive to the external regions of the particle, thereby protecting them from the action of oxidant agents (Weiss et al., 2008; Tikekar et al., 2011). Vegetable butters, as cupuacu, are excellent raw materials for 
producing solid lipid nanoparticles because these butters are composed of mixtures of different triglycerides.

Solid lipid nanoparticles, similar to nanoemulsions, are thermodynamically unstable and require energy input for formation. This energy can be supplied by high-energy methods, or the chemical energy of components stored in the system (Solé et al., 2006). High-energy methods involve the use of specific devices, such as high-shear stirrers, high pressure homogenizers, microfluidizers, and ultrasound generators (McClements and Rao, 2011), to produce intense disruptive forces. A disadvantage of this approach is that the smaller the droplet size, the higher the surfactant and/or energy requirements of the system. By contrast, lowenergy emulsification methods employ the intrinsic physicochemical properties of the system, as changes in the spontaneous curvature of the surfactant, to produce nanoemulsions (Fernandez et al., 2004; Solans and Solè, 2012). Furthermore, low-energy methods generally allow production of much smaller droplet sizes than those obtained through high-energy processes (Anton and Vandamme, 2009).

The phase inversion temperature (PIT) method is a low-energy method based on the particular ability of polyethoxylated (PEO) nonionic surfactants to become dehydrated with heating, thereby altering their hydrophilic-lipophilic balance. In the PIT method, the surfactant is hydrophilic at low temperatures but becomes lipophilic with increasing temperature because of dehydration of the polyoxyethylene chains. Then, at a specific temperature (also called the PIT temperature, $T_{\mathrm{PIT}}$ ), the emulsion is inverted. If the system is quickly cooled, the surfactant becomes hydrophilic once more and very small droplets can be produced (Anton and Vandamme, 2009). This method can also be used to produce solid lipid nanoparticles (Montenegro et al., 2011a; Montenegro et al., 2011b).

To investigate the bioavailability of encapsulated bioactives in lipid nanoparticles, in vitro static and dynamic digestion models have been developed to investigate the physicochemical processes associated with digestion (Pinheiro et al., 2013). Dynamic in vitro models have attempted to simulate digestion in continuous mode with multiple compartments; the mechanical events (e.g., peristaltic movements) of digestion have also been studied (Reis et al., 2008). One of the dynamic in vitro digestion simulation systems is the TNO intestinal model, a multicompartment dynamic system controlled by computational systems that simulate the in vivo conditions and kinetic events in the human gastrointestinal tract. These events include $\mathrm{pH}$ changes, temperature, peristaltic movements, juices secretion, and absorption of digestion products by the intestinal mucosa (McCallister, 2010).

The present research work aimed to produce beta-carotene loaded solid lipid nanoparticles from cupuacu (Theobroma grandiflorum) butter via the PIT method. The physicochemical stability of the nanoparticles was evaluated over a storage period of 120 days and under different stress conditions (i.e., heat, ionic strength, and sucrose), and a comparison of their static and dynamic in vitro digestibilities was carried out.

\section{Materials and methods}

\subsection{Materials}

Nanoemulsions were produced using cupuacu butter (T. grandiflorum) (Jacy Fragrâncias, Santa Bárbara D'Oeste, SP, Brazil). Beta-carotene and alpha-tocopherol and span 80 were obtained from Sigma-Aldrich (St. Louis, MO, USA). Cremophor RH40 (40PEG hydroxylated castor oil) was obtained from BASF (Ludwigshafen, Germany). All of the reagents used in the in vitro digestibility experiments were purchased from Sigma-Aldrich (St
Louis, MO, USA) and of reagent grade. Ultrapure water (from a Millipore system, Millipore, Billerica, MA, USA) was used throughout the experiments. All other chemicals used were reagent grade.

\subsection{Production of the lipid nanoparticles by the PIT method}

The nanoemulsions formulations contained, in $100 \mathrm{~g}$ of nanoemulsions: $80 \mathrm{~g}$ of deionized water, $12 \mathrm{~g}$ of Cremophor RH 40, $8 \mathrm{~g}$ of Span 80, and $10 \mathrm{~g}$ of cupuacu butter. A hot dispersion of the surfactants was dispersed in melted cupuacu butter through mechanical stirring at $500 \mathrm{rpm}$. The emulsion was then submitted to two heating and cooling cycles. Beta-carotene $(0.6 \mathrm{~g})$ and alphatocopherol (when present, $0.3 \mathrm{~g}$ ) were added to the mixture in the second heating cycle. Curves of conductivity (obtained using a Inolab 740, WTW, Weilheim, Germany) versus temperature were plotted, and the $\mathrm{T}_{\mathrm{PIT}}$ was determined from the average temperature between the onset of decrease in conductivity and the minimum temperature reached by the system after phase inversion. The system was heated to $80{ }^{\circ} \mathrm{C}$ (by placing the beckers with the mixture of surfactants and cupuacu butter in a thermostatized bath) and cooled to $20{ }^{\circ} \mathrm{C}$ (by placing the dispersions in jacketed vessels cooled by water at $2^{\circ} \mathrm{C}$ ). The cooling and heating rates were 10 and $6{ }^{\circ} \mathrm{C} / \mathrm{min}$, respectively.

\subsection{Determination of average particle size, particle size distribution, and polydispersity}

The average hydrodynamic diameter, particle size distribution and polydispersity (PDI) of the nanoparticles were determined using dynamic light scattering (quasi-elastic light scattering) ZetaPlus equipment (Brookhaven Instruments Company, Holtsville, NY, USA) at $25^{\circ} \mathrm{C}$. The samples were diluted with ultra-purified water to prevent multiple light scattering. Data analyses were performed using the software included with the system (90Plus/BiMAS).

\subsection{Quantification of beta-carotene}

The quantification of beta-carotene in the lipid nanoparticles was carried out according to Cornacchia and Roos (2011a). The sample of lipid nanoparticles was diluted with deionized water $(100 \times)$. Two mililiters of this dilution was mixed with $1.5 \mathrm{~mL}$ of ethanol and $1 \mathrm{~mL}$ of methanol saturated with $\mathrm{KOH}$. After vortexing, the mixture was heated to $45^{\circ} \mathrm{C}$ for $30 \mathrm{~min}$. Beta-carotene was extracted after washing the total volume of this vortexed mixture $(4.5 \mathrm{~mL})$ three times with $2 \mathrm{~mL}$ of $\mathrm{n}$-hexane containing $0.1 \%(\mathrm{w} / \mathrm{v})$ butylated hydroxytoluene. The organic solvent was added to the emulsion, after which the mixture was stirred and then left to stand for $10 \mathrm{~min}$. The organic layer, which contained beta-carotene, was carefully removed and its absorbance was obtained spectrophotometrically (Libra 22S, Biochrom, Cambridge, UK) at $450 \mathrm{~nm}$.

\subsection{Quantification of alpha-tocopherol}

Alpha-tocopherol was extracted from the lipid nanoparticles using the same protocol described for beta-carotene extraction (Section 2.3). However, after emulsion destabilization and phase demixing, the top layer, which contained alpha-tocopherol, was analyzed by spectrofluorometry (LS55, Perkin Elmer, Waltham, MA, USA) at excitation and emission wavelengths of 290 and $327 \mathrm{~nm}$, respectively (Relkin and Shukat, 2012). 


\subsection{Thermal behavior of lipid nanoparticles by differential scanning calorimetry (DSC)}

The thermal analyses of the lipid naniparticles were performed using DSC with a ramp of $10^{\circ} \mathrm{C} / \mathrm{min}$ in the range of $0-90{ }^{\circ} \mathrm{C}$ on a TA5000 (TA Instruments, New Castle, DE, USA). The samples (10 mg) were placed in hermetically sealed aluminum TA pans and heated from $0{ }^{\circ} \mathrm{C}$ to $90{ }^{\circ} \mathrm{C}$ using a heating ramp of $10{ }^{\circ} \mathrm{C} / \mathrm{min}$. An empty pan was used as a reference. The heating was performed under an inert atmosphere $\left(45 \mathrm{~mL} / \mathrm{min} \mathrm{N}_{2}\right)$. The results were analyzed with the Universal Analysis V1.7 F software (TA Instruments, New Castle, DE, USA). The runs were performed in duplicate.

\subsection{Physicochemical stability of lipid nanoparticles under stress conditions}

The physicochemical stability of the nanoemulsions was assessed by measuring their average particle size and quantifying their beta-carotene content.

Thermal treatments: Samples were heated to $35,55,75$, or $95^{\circ} \mathrm{C}$ by placing test tubes containing the nanodispersions in a water bath.

Influence of ionic strength: Different amounts of $\mathrm{NaCl}$ were added to the particle dispersions to obtain salt concentrations between 0.025 and $1.0 \mathrm{M}$. The nanoemulsions were vigorously shaken and stored under refrigeration.

Influence of sugar concentration: Different amounts of sucrose were added to the particle dispersions, resulting in sucrose concentrations ranging from $1.5 \%$ to $15 \%(\mathrm{w} / \mathrm{v})$. The nanoemulsions were vigorously shaken and stored under refrigeration.

\subsection{Transmission electron microscopy (TEM)}

TEM images were obtained by an EM 902A microscope (Zeiss, Jena, Germany) at an accelerating voltage of $80 \mathrm{kV}$. The samples were prepared by dropping the nanoemulsions onto copper grids coated with carbon film, followed by staining with uranyl acetate and natural drying.

\subsection{Evaluation of in vitro digestibility}

Two types of in vitro digestion systems (static and dynamic) were used to evaluate the digestibility of the nanoparticles and the bioaccessibility of beta-carotene. In both cases, the following gastric, duodenal, jejunal, and ileal secretions were used (Pinheiro et al., 2016):

Gastric fluid: pepsin and lipase in a gastric electrolyte solution of salts (4.8 g/L NaCl, $\left.2.2 \mathrm{~g} / \mathrm{L} \mathrm{KCl}, 0.22 \mathrm{~g} / \mathrm{L} \mathrm{CaCl}_{2}, 1.5 \mathrm{~g} / \mathrm{L} \mathrm{NaHCO}_{3}\right)$.

Duodenal fluid: $4 \%(\mathrm{w} / \mathrm{v})$ of swine bile extract, $7 \%(\mathrm{w} / \mathrm{v})$ of pancreatin solution, $20 \mathrm{~mL}$ of SIES (small intestinal electrolytic solution) $\left(5 \mathrm{~g} / \mathrm{L} \mathrm{NaCl}, 0.6 \mathrm{~g} / \mathrm{L} \mathrm{KCl}, 0.25 \mathrm{~g} / \mathrm{L} \mathrm{CaCl}_{2}\right)$.

Jejunal fluid: SIES and $10 \%(\mathrm{w} / \mathrm{v})$ of porcine bile extract.

Ileal fluid: only SIES.

The static assays were carried out in a double-walled waterjacketed reactor vessel at $37{ }^{\circ} \mathrm{C}$ under magnetic stirring (Ahmed et al., 2012). Forty mililiters of the nanoparticle dispersion was placed in the reactor and then mixed with the appropriate secretions to mimic the physiological conditions of the GI tract. For stomach digestion simulation, nanoparticle dispersions were mixed with the gastric fluid and the $\mathrm{pH}$ was adjusted to 1.7. The mixture was maintained at $37^{\circ} \mathrm{C}$ under magnetic stirring for $2 \mathrm{~h}$. Later, $40 \mathrm{~mL}$ of this mixture was added to the duodenal simulation fluid, and the $\mathrm{pH}$ was adjusted to 6.5. This mixture was maintained for $2 \mathrm{~h}$ at $37^{\circ} \mathrm{C}$.
A dynamic in vitro gastrointestinal system was used for the digestion simulation. The equipment consisted of four compartments corresponding to the stomach, duodenum, jejunum, and ileum. Water is pumped around flexible walls to maintain a temperature at $37^{\circ} \mathrm{C}$ and enable simulation of peristaltic movements. Changes in water pressure are achieved by peristaltic pumps, which alter the flow direction according to the time-controlled devices connected to them. The compartments are connected by silicone tubes and injected with a constant volume of chyme. All of the compartments have $\mathrm{pH}$ electrodes, and $\mathrm{pH}$ values are controlled by addition of $\mathrm{HCl}$ to the stomach and $\mathrm{NaHCO}_{3}$ into the intestinal compartments. Gastric and intestinal secretions are added via syringe pumps at pre-set flow rates. The jejunum and ileum compartments are connected to hollow-fiber devices to absorb digestion products and water, as well as modify the electrolyte and bile salt concentrations in the chyme (Reis et al., 2008).

The digestion protocol was based on Pinheiro et al. (2016). Forty mililiters of the nanoparticle dispersion were introduced to the gastric compartment, and the experiment was run for a total of $5 \mathrm{~h}$. The average physiological conditions of the GI tract were simulated by continuous addition of gastric, duodenal, jejunal, and ileal secretions. The gastric secretion was added at a flow rate of $0.33 \mathrm{~mL} /$ min, and the $\mathrm{pH}$ was controlled to follow a predetermined curve (from 4.8 at $t=0$ to 1.7 at $t=120 \mathrm{~min}$ ) by secreting $\mathrm{HCl} 1 \mathrm{M}$. The duodenal, jejunal, and ileal secretions were secreted at flow rates of $0.66,2.13$, and $2.0 \mathrm{~mL} / \mathrm{min}$, respectively. The $\mathrm{pH}$ values in the simulated duodenum, jejunum, and ileum were controlled at the values of $6.5,6.8$, and 7.2 , respectively.

During in vitro digestion, samples were collected directly from the lumen of the different compartments, from the jejunal and ileal filtrates, and from the ileal delivery. The samples were analyzed for particle size, zeta-potential, free fatty acids, and bioaccessibility of beta-carotene.

\subsubsection{Quantification of free fatty acid release}

Free fatty acid release was measured by titration with $\mathrm{NaOH}$, and the volume of $\mathrm{NaOH}$ added to the emulsion was recorded and used to calculate the concentration of free fatty acids generated by lipolysis through the equation:

$\% F F A=100 \times\left(\frac{V_{\mathrm{NaOH}} \times M_{\mathrm{NaOH}} \times M M_{\text {lipid }}}{w_{\text {lipid }} \times 2}\right)$

where: \%FFA $=$ percentage of released free fatty acids; $\mathrm{V}_{\mathrm{NaOH}}=$ volume of sodium hydroxyde used in the titration (in $\mathrm{mL}$ ); $\mathrm{M}_{\mathrm{NaOH}}=$ molarity of $\mathrm{NaOH}$ solution; $\mathrm{MM}_{\text {lipid }}=$ molecular mass of the reference lipid $\left(284.5 \mathrm{~g} / \mathrm{mol}\right.$ for stearic acid); $\mathrm{w}_{\text {lipid }}=$ initial mass of lipid (in grams) (Bonnaire et al., 2008).

\subsubsection{Determination of beta-carotene bioaccessibility}

Quantification of beta-carotene bioaccessibility was carried out according to Salvia-Trujillo et al. (2013). An aliquot of the raw digesta was centrifuged at $4000 \mathrm{rpm}$ for $40 \mathrm{~min}$ at $25^{\circ} \mathrm{C}$. The supernatant was then collected and considered the "micelle fraction" in which the bioactive compound was "solubilized". Aliquots of $5 \mathrm{~mL}$ of raw digesta or the micelle fraction were mixed with $5 \mathrm{~mL}$ of chloroform, vortexed, and then centrifuged at $1750 \mathrm{rpm}$ for $10 \mathrm{~min}$ at $25^{\circ} \mathrm{C}$. The top layer was mixed with $5 \mathrm{~mL}$ of chloroform and extracted once more. The bottom chloroform layer was added to the previously collected layer, and the absorbance of this solution was measured at $450 \mathrm{~nm}$ using a spectrophotometer. 


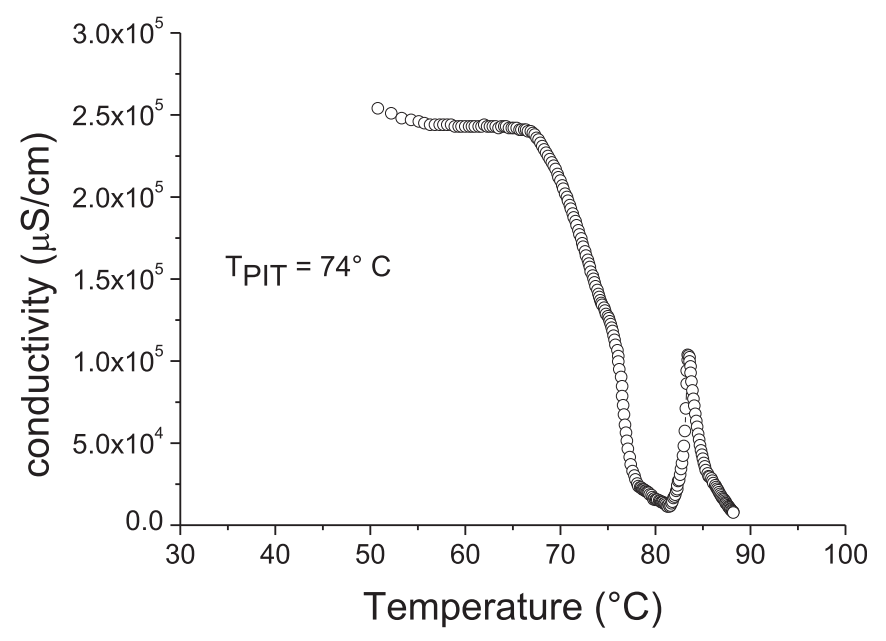

Fig. 1. Conductivity $v s$. temperature curve for the phase inversion temperature of the dispersions with cupuacu butter as oil phase and the mixture Cremophor RH40 and Span 80 as surfactants.

\subsection{Statistical analyses}

Statistical analyses were carried out via analysis of variance, Tukey's mean comparison test $(p<0.05)$, and linear regression analysis using SAS 9.2 software (SAS Institute Corporation, Cary, NC, USA).

\section{Results and discussion}

\subsection{Production of lipid nanoparticles by the PIT method and evaluation of their physicochemical stability}

The $\mathrm{T}_{\mathrm{PIT}}$ of the nanoparticles was determined through conductivity measurements, shown in Fig. 1 , and its value was $74^{\circ} \mathrm{C}$. The peak of conductivity after phase inversion reflects some structures of the liquid crystalline phase and bicontinuous phases typically associated with the formation of nanoemulsions or nanoparticles (Izquierdo et al., 2004). According to Anton et al. (2008), peaks of conductivity arise when surfactant concentration is high (more than around $9 \%$ in mass). In the cited study, different structures (liquid crystalline structures) were distinguished as the temperature rose, which resembled a lamellar phase, as it was birefringent. The transitional region of emulsion phase inversion is in most cases due to the formation at equilibrium of a "D-type" bicontinuous microemulsion (which is a lamellar phase), and it can in fact be either a Winsor III (oil + water + bicontinuous emulsion) or Winsor IV (only bicontinuous emulsion), as a function of the value of SOR (surfactant/oil ratio) (Morales et al., 2003). Therefore, the evolution of these nanostructures exhibiting different conductivity profiles as a function of temperature depends on the surfactant interfacial concentration. Therefore, the conductivity peak, as well as the curve shift, may come from such surfactant interfacial behavior. Regarding electrical conductivity, the reason why a rise is observed when a liquid crystalline phase forms at equilibrium still remains poorly understood. It is supposed that the intermediary geometries formed during phase inversion may create conductive channels between the two electrodes of the conductivimeter, resulting in an apparent temperature rise (Anton et al., 2008).

Beta-carotene-loaded lipid nanoparticles with and without alpha-tocopherol were then produced. Incorporation of betacarotene into the lipid nanoparticles did not seem to alter their average particle diameter, which changed from $31.6 \pm 0.2 \mathrm{~nm}$ (empty lipid nanoparticles) to $34.08 \pm 0.5 \mathrm{~nm}$ (beta-caroteneloaded lipid nanoparticles), significantly. Fig. 2 shows the particle size distribution curves of these nanoparticles over a storage period of 120 days under refrigeration, in the dark. All of the samples presented extremely high stability during the storage period in terms of hydrodynamic diameter and particle size distribution; such a characteristic can be attributed to the absence of coalescence arising from the highly reduced average size of the particles (around $40 \mathrm{~nm}$ ) and the limitation of Ostwald ripening, as solid lipids are the components of the dispersed phase (Wooster et al., 2008).

The thermal behavior of the lipid nanoparticles may be represented by the DSC thermograms shown in Fig. 3. The melting peak of the lipid nanoparticles $\left(12-13^{\circ} \mathrm{C}\right)$ was detected at a temperature lower than the melting temperature of bulk cupuacu butter $\left(32^{\circ} \mathrm{C}\right.$, data not shown), and this result is in good agreement with the Gibbs-Thomson equation (Bunjes and Unruh, 2007), which states that the smaller the average particle size, the higher the decrease in melting temperature:

$\ln \frac{T}{T_{0}}=\frac{2 \gamma_{s l} V_{S}}{r \Delta H_{f u s}}$

where $T$ is the melting temperature of particles with radius $r, T_{0}$ is the bulk temperature of the lipid, $\gamma_{s l}$ is the solid-liquid interfacial tension, $V_{S}$ is the specific volume of the solid, and $\Delta H_{\text {fus }}$ is the fusion heat of the pure solid.

The presence of alpha-tocopherol did not significantly affect the thermal behavior of the lipid nanoparticles. The broad transition peaks and low melting enthalpies $\left(\Delta \mathrm{H}_{\mathrm{m}}\right)$ of the nanoparticles confirmed that the lipid core is composed of multi-component
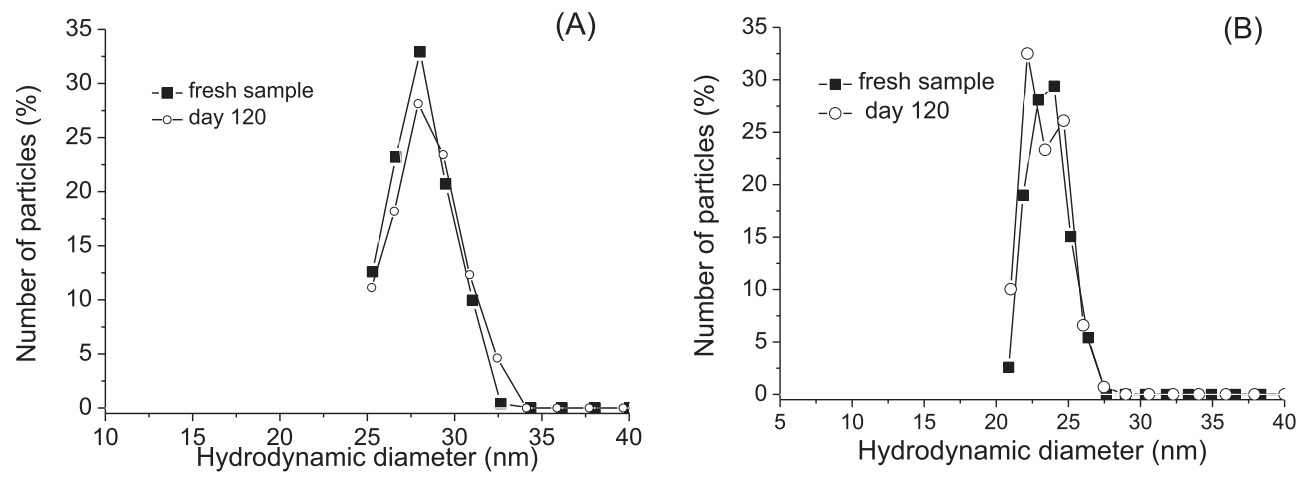

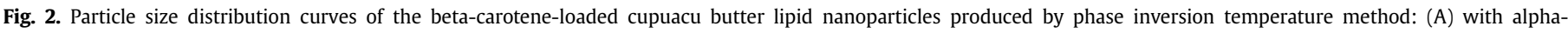
tocopherol; (B) without alpha-tocopherol. 


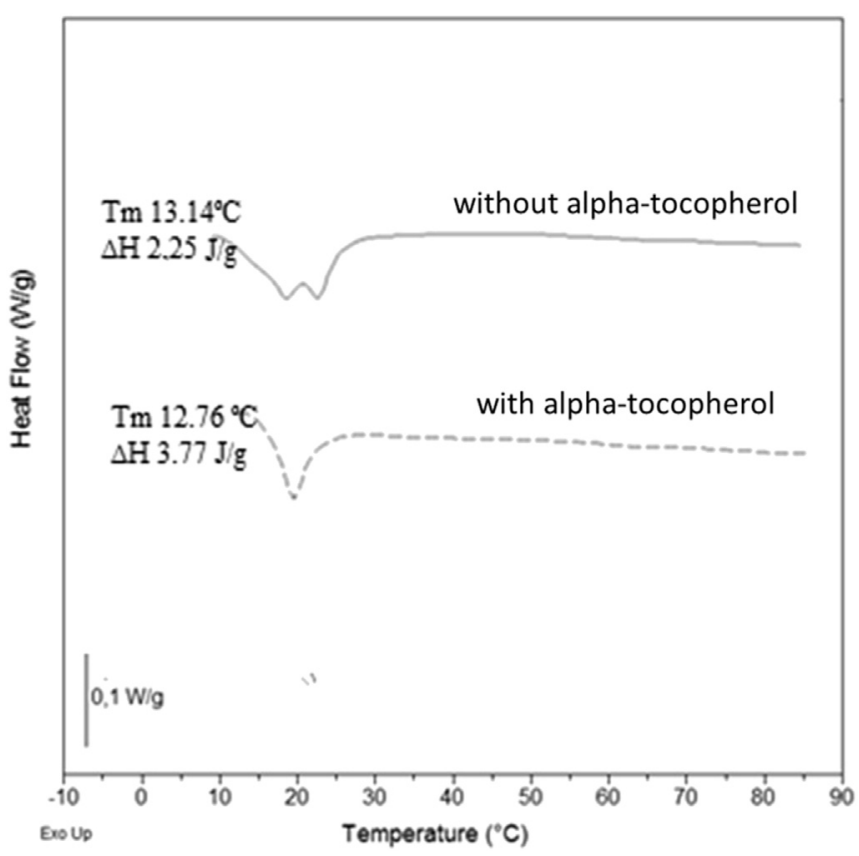

Fig. 3. Thermal behavior obtained by differential scanning calorimetry for the cupuacu butter lipid nanoparticles.

disordered matrices with imperfections in their structures. Such a morphology could promote better accommodation of the betacarotene molecules into the nanoparticle structure, thereby preventing its expulsion to the external regions of the lipid nanoparticles (Müller et al., 2000; Tikekar and Nitin, 2011).

Fig. 4 shows the concentration profiles $\left(C / C_{0}\right)$ of encapsulated beta-carotene and alpha-tocopherol as a function of time. After 120 days, approximately $90 \%$ of the initial amount of the carotenoid remained preserved in the nanoparticles with alpha-tocopherol. Lipid nanoparticles without alpha-tocopherol protected betacarotene less efficiently; in these nanoparticles, about $30 \%$ of the initial amount of beta-carotene was degraded over 40 days of storage.

Both types of nanoparticles showed similar behaviors, with a beta-carotene loss of about $10 \%$, up to the seventh day of storage. After this period, however, the beta-carotene-loaded nanoparticles containing alpha-tocopherol were able to preserve $90 \%$ of the initial mass of encapsulated carotenoid for up to 90 days, at which point the beta-carotene amount began to decline. The final amount of beta-carotene was similar in both nanodispersions, with $70 \%$ of the beta-carotene remaining preserved in the particles. The alpha-
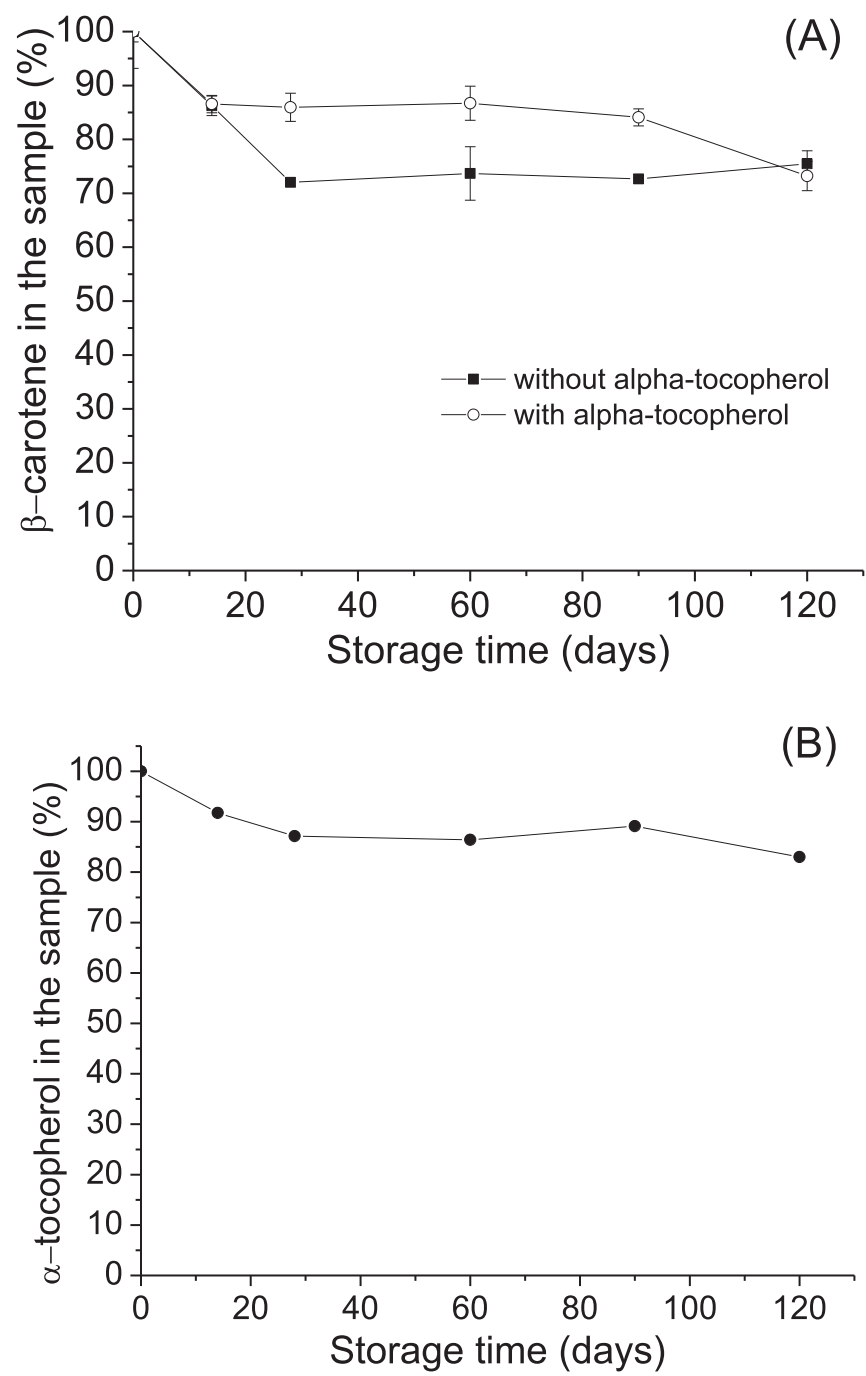

Fig. 4. Temporal profile over storage period of the encapsulated compounds in the cupuacu butter lipid nanoparticles: (A) beta-carotene; (B) alpha-tocopherol.

tocopherol-loaded nanoparticles demonstrated the same tendency, showing a decrease in the compound up to 21 days of storage and then maintaining alpha-tocopherol concentrations up to 90 days.

Comparing the physicochemical stability of our encapsulated beta-carotene with other sets of data from previous studies on nanoemulsions and lipid nanoparticles encapsulating beta-

Table 1

Average particle size and concentration of beta-carotene in the cupuacu butter lipid nanoparticles before and after thermal stresses.

\begin{tabular}{|c|c|c|c|c|}
\hline \multirow[t]{2}{*}{ Stress condition } & \multicolumn{2}{|c|}{ Lipid nanoparticles without alpha-tocopherol } & \multicolumn{2}{|c|}{ Lipid nanoparticles with alpha-tocopherol } \\
\hline & Average particle diameter $(\mathrm{nm})$ & Beta-carotene $(\mu \mathrm{g} / \mathrm{mL})$ & Average particle diameter $(\mathrm{nm})$ & Beta-carotene $(\mu \mathrm{g} / \mathrm{mL})$ \\
\hline No stress (control) & $34.2 \pm 0.1^{\mathrm{A}, \mathrm{a}}$ & $96.7 \pm 1.5^{\mathrm{A}, \mathrm{a}}$ & $34.1 \pm 0.5^{\mathrm{A}, \mathrm{a}}$ & $97.5 \pm 0.9^{\mathrm{A}, \mathrm{a}}$ \\
\hline $35^{\circ} \mathrm{C}, 5 \mathrm{~min}$ & $34.5 \pm 0.1^{\mathrm{A}, \mathrm{a}}$ & $96.9 \pm 9.1^{\mathrm{A}, \mathrm{a}}$ & $34.1 \pm 0.4^{\mathrm{A}, \mathrm{a}}$ & $97.0 \pm 0.1^{\mathrm{A}, \mathrm{a}}$ \\
\hline $35^{\circ} \mathrm{C}, 15 \mathrm{~min}$ & $34.6 \pm 0.4^{\mathrm{A}, \mathrm{a}}$ & $98.0 \pm 1.2^{\mathrm{A}, \mathrm{a}}$ & $33.6 \pm 0.2^{\mathrm{A}, \mathrm{a}}$ & $99.2 \pm 0.5^{\mathrm{A}, \mathrm{a}}$ \\
\hline $50^{\circ} \mathrm{C}, 5 \mathrm{~min}$ & $34.2 \pm 1.0^{\mathrm{A}, \mathrm{a}}$ & $96.9 \pm 9.1^{\mathrm{A}, \mathrm{a}}$ & $34.9 \pm 0.6^{\mathrm{A}, \mathrm{a}}$ & $97.3 \pm 4.3^{\mathrm{A}, \mathrm{a}}$ \\
\hline $50^{\circ} \mathrm{C}, 15 \mathrm{~min}$ & $36.8 \pm 0.1^{\mathrm{A}, \mathrm{a}}$ & $83.3 \pm 2.9^{\mathrm{B}, \mathrm{b}}$ & $36.2 \pm 0.8^{\mathrm{A}, \mathrm{a}}$ & $90.3 \pm 1.9^{\mathrm{B}, \mathrm{a}}$ \\
\hline $75^{\circ} \mathrm{C}, 5 \mathrm{~min}$ & $35.4 \pm 0.8^{\mathrm{A}, \mathrm{a}}$ & $91.9 \pm 5.8^{\mathrm{B}, \mathrm{b}}$ & $34.3 \pm 0.1^{\mathrm{A}, \mathrm{a}}$ & $98.8 \pm 0.1^{\mathrm{A}, \mathrm{a}}$ \\
\hline $75^{\circ} \mathrm{C}, 15 \mathrm{~min}$ & $35.2 \pm 0.1^{\mathrm{A}, \mathrm{a}}$ & $81.8 \pm 1.7^{\mathrm{BC}, \mathrm{bc}}$ & $34.0 \pm 0.3^{\mathrm{A}, \mathrm{a}}$ & $91.9 \pm 5.8^{\mathrm{B}, \mathrm{a}}$ \\
\hline $95^{\circ} \mathrm{C}, 5 \mathrm{~min}$ & $34.8 \pm 0.3^{\mathrm{A}, \mathrm{a}}$ & $78.4 \pm 0.3^{\mathrm{C}, \mathrm{c}}$ & $35.5 \pm 0.1^{\mathrm{A}, \mathrm{a}}$ & $92.2 \pm 5.2^{\mathrm{B}, \mathrm{a}}$ \\
\hline $95^{\circ} \mathrm{C}, 15 \mathrm{~min}$ & $32.4 \pm 0.1^{\mathrm{A}, \mathrm{a}}$ & $72.4 \pm 2.9^{\mathrm{C}, \mathrm{b}}$ & $33.9 \pm 0.2^{\mathrm{A}, \mathrm{a}}$ & $86.7 \pm 4.8^{\mathrm{B}, \mathrm{a}}$ \\
\hline
\end{tabular}

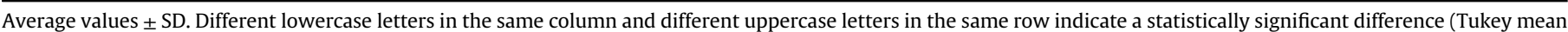
comparison test, $p<0.05$ ), for each type of lipid nanoparticles. 
Table 2

Average particle size and concentration of beta-carotene in the cupuacu butter lipid nanoparticles under different ionic strength conditions.

\begin{tabular}{|c|c|c|c|c|}
\hline \multirow[t]{2}{*}{ Condition } & \multicolumn{2}{|c|}{ Lipid nanoparticles without alpha-tocopherol } & \multicolumn{2}{|c|}{ Lipid nanoparticles with alpha-tocopherol } \\
\hline & Average particle diameter (nm) & Beta-carotene $(\mu \mathrm{g} / \mathrm{mL})$ & Average particle diameter (nm) & Beta-carotene $(\mu \mathrm{g} / \mathrm{mL})$ \\
\hline No stress (control) & $34.2 \pm 0.1^{\mathrm{A}, \mathrm{a}}$ & $96.7 \pm 1.5^{\mathrm{A}, \mathrm{a}}$ & $34.1 \pm 0.5^{\mathrm{A}, \mathrm{a}}$ & $97.5 \pm 0.9^{\mathrm{A}, \mathrm{a}}$ \\
\hline $1.5 \%$ sucrose & $32.9 \pm 0.1^{\mathrm{A}, \mathrm{a}}$ & $85.28 \pm 2.5^{\mathrm{B}, \mathrm{b}}$ & $35.2 \pm 1.0^{\mathrm{A}, \mathrm{a}}$ & $92.7 \pm 1.8^{\mathrm{A}, \mathrm{ab}}$ \\
\hline $3.0 \%$ sucrose & $33.3 \pm 0.2^{\mathrm{A}, \mathrm{a}}$ & $75.7 \pm 0.1^{\mathrm{c}, \mathrm{b}}$ & $33.8 \pm 0.1^{\mathrm{A}, \mathrm{a}}$ & $92.7 \pm 1.8^{\mathrm{B}, \mathrm{a}}$ \\
\hline $5.0 \%$ sucrose & $35.9 \pm 0.1^{\mathrm{A}, \mathrm{a}}$ & $72.3 \pm 3.2^{\mathrm{CD}, \mathrm{d}}$ & $35.2 \pm 0.7^{\mathrm{A}, \mathrm{a}}$ & $92.7 \pm 1.8^{\mathrm{B}, \mathrm{a}}$ \\
\hline $7.5 \%$ sucrose & $34.8 \pm 0.1^{\mathrm{A}, \mathrm{a}}$ & $69.6 \pm 1.4^{\mathrm{D}, \mathrm{d}}$ & $36.0 \pm 0.4^{\mathrm{A}, \mathrm{a}}$ & $83.2 \pm 2.6^{\text {C.b }}$ \\
\hline
\end{tabular}

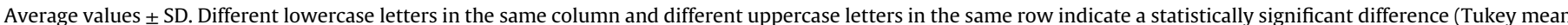
comparison test, $p<0.05$ ), for each type of lipid nanoparticles.

Table 3

Average particle size and concentration of beta-carotene in the cupuacu butter lipid nanoparticles under different sucrose concentrations.

\begin{tabular}{|c|c|c|c|c|}
\hline \multirow[t]{2}{*}{ Condition } & \multicolumn{2}{|c|}{ Lipid nanoparticles without alpha-tocopherol } & \multicolumn{2}{|c|}{ Lipid nanoparticles with alpha-tocopherol } \\
\hline & Average particle diameter (nm) & Beta-carotene $(\mu \mathrm{g} / \mathrm{mL})$ & Average particle diameter (nm) & Beta-carotene $(\mu \mathrm{g} / \mathrm{mL})$ \\
\hline No stress (control) & $34.2 \pm 0.1^{\mathrm{A}, \mathrm{a}}$ & $96.7 \pm 1.5^{\mathrm{A}, \mathrm{a}}$ & $34.1 \pm 0.5^{\mathrm{A}, \mathrm{a}}$ & $97.5 \pm 0.9^{\mathrm{A}, \mathrm{a}}$ \\
\hline $0.025 \mathrm{M} \mathrm{NaCl}$ & $38.9 \pm 0.1^{\mathrm{B}, \mathrm{b}}$ & $86.4 \pm 0.6^{\mathrm{B}, \mathrm{ab}}$ & $35.2 \pm 0.4^{\mathrm{A}, \mathrm{a}}$ & $84.2 \pm 9.4^{\mathrm{B}, \mathrm{b}}$ \\
\hline $0.10 \mathrm{M} \mathrm{NaCl}$ & $41.9 \pm 0.3^{\mathrm{C}, \mathrm{a}}$ & $80.3 \pm 0.7^{\mathrm{B}, \mathrm{b}}$ & $41.6 \pm 0.3^{\mathrm{B}, \mathrm{a}}$ & $83.9 \pm 1.7^{\mathrm{B}, \mathrm{b}}$ \\
\hline $0.25 \mathrm{M} \mathrm{NaCl}$ & $43.4 \pm 0.6^{\mathrm{D}, \mathrm{a}}$ & $79.9 \pm 1.3^{\mathrm{BC}, \mathrm{b}}$ & $41.4 \pm 0.3^{\mathrm{B}, \mathrm{a}}$ & $81.3 \pm 0.3^{\mathrm{B}, \mathrm{b}}$ \\
\hline $0.50 \mathrm{M} \mathrm{NaCl}$ & $42.9 \pm 0.1^{\mathrm{CD}, \mathrm{a}}$ & $75.7 \pm 0.4^{\mathrm{C,c}}$ & $43.2 \pm 0.3^{\mathrm{B}, \mathrm{a}}$ & $82.3 \pm 0.6^{\mathrm{B}, \mathrm{b}}$ \\
\hline $1.0 \mathrm{M} \mathrm{NaCl}$ & $42.6 \pm 0.1^{\mathrm{C}, \mathrm{a}}$ & $65.6 \pm 0.2^{\mathrm{D}, \mathrm{b}}$ & $42.2 \pm 0.5^{\mathrm{B}, \mathrm{a}}$ & $68.5 \pm 3.8^{\mathrm{C}, \mathrm{b}}$ \\
\hline
\end{tabular}

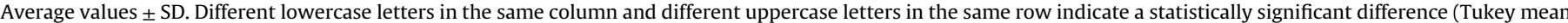
comparison test, $p<0.05$ ), for each type of lipid nanoparticles.

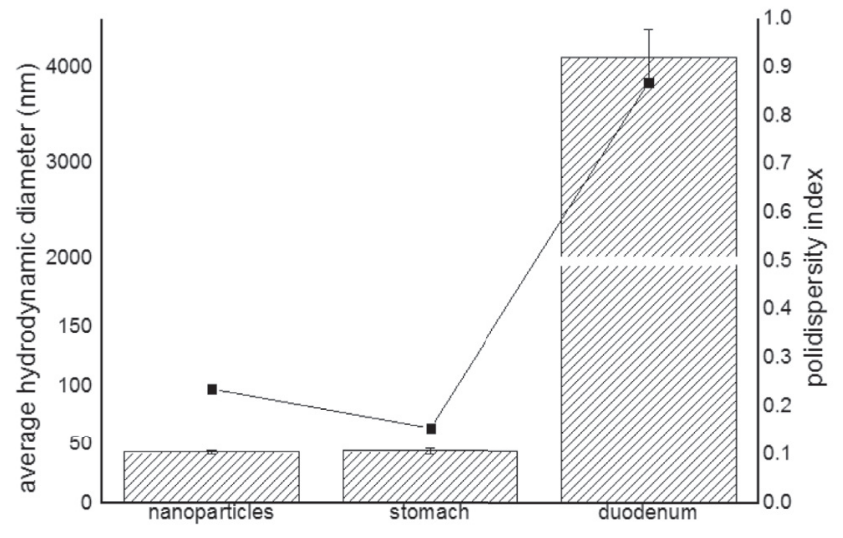

(A)

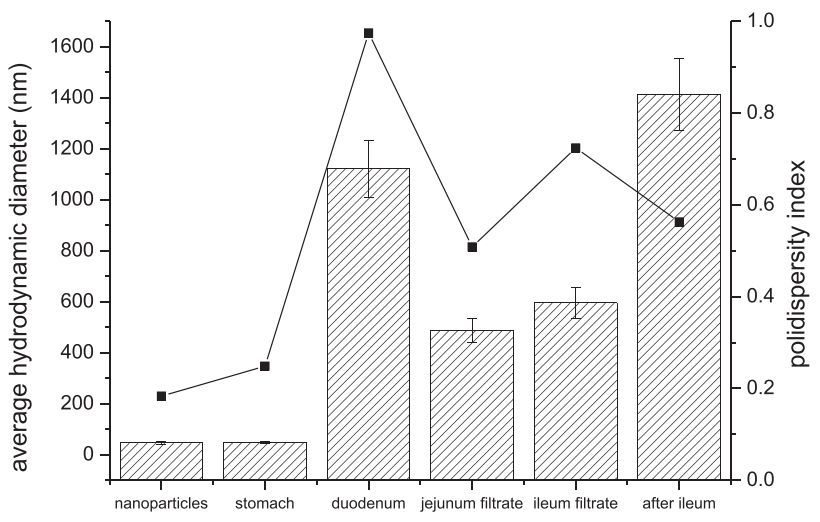

(C)

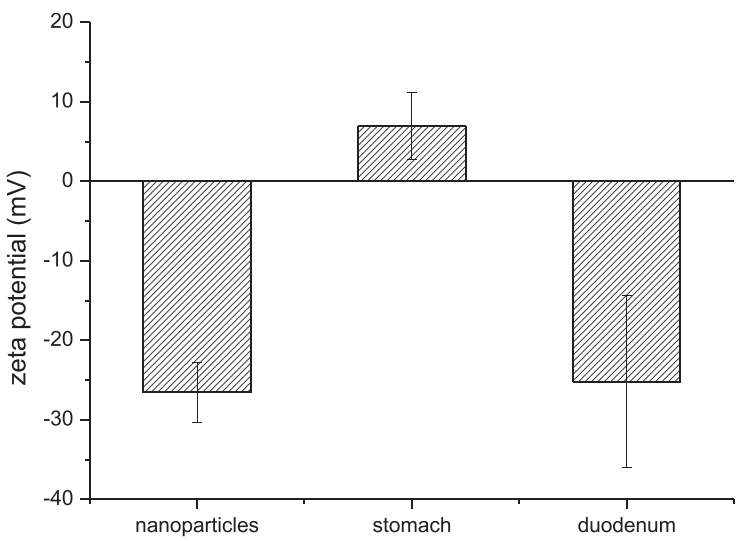

(B)

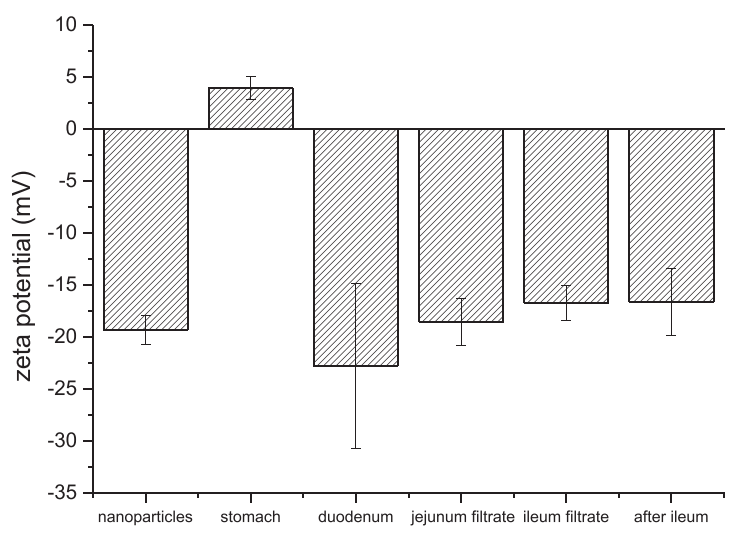

(D)

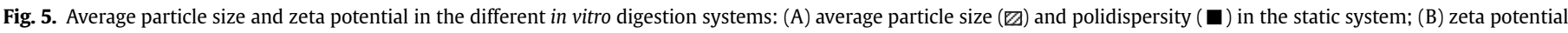
in the static system; (C) average particle size (四) and polidispersity ( $\mathbf{\square})$ in the dynamic system; (D) zeta potential in the dynamic system. 


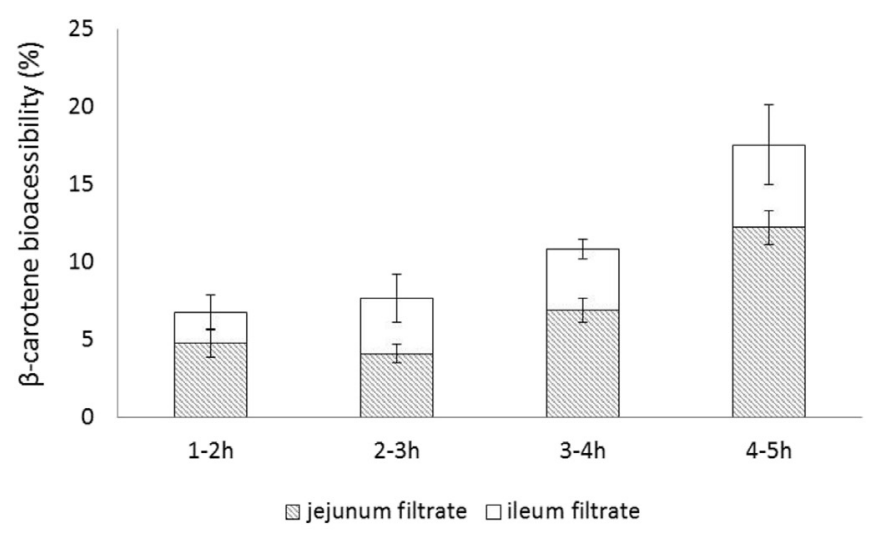

(A)

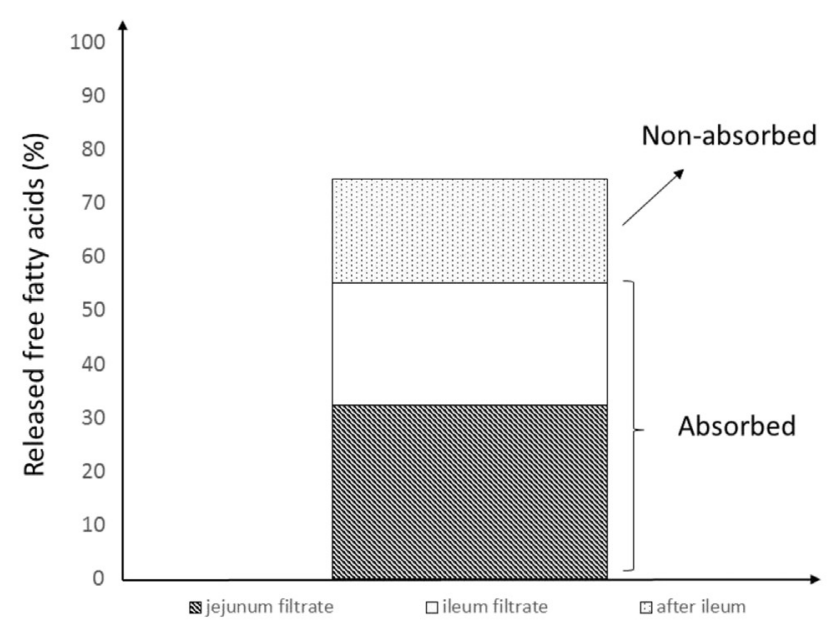

(B)

Fig. 6. (A) Total bioacessibility of the beta-carotene along the gastrointestinal tract in the dynamic in vitro digestion system. The values are represented in \% of the initial amount of the carotenoid present in the samples of lipid nanoparticles. (B) Free fatty acids (FFA) released from the cupuacu butter lipid nanoparticles along the dynamic in vitro digestion system.

carotene stored at low temperatures, such as those of Tan and Nakajima (2005), Cornacchia and Roos (2011a, 2011b) and Qian et al. (2012), we observed similar preservation characteristics. The need for coencapsulation with an antioxidant to protect encapsulated beta-carotene has been also realized in other studies (Hentschel et al., 2008; Tikekar et al., 2011; Gomes et al., 2013).

Table 1 clearly shows that even when the nanoparticles were submitted to the most extreme heat stress condition $\left(95^{\circ} \mathrm{C}\right.$ for $15 \mathrm{~min}$ ), in none of the cases was the average particle size significantly altered. The beta-carotene concentration indicated that it was, especially that in nanoparticles containing alpha-tocopherol, was well-protected from extreme stress. When heated to $95{ }^{\circ} \mathrm{C}$ for $15 \mathrm{~min}$, only a $10 \%$ loss of beta-carotene was observed in the alpha-tocopherol-loaded nanoparticles. Even in the dispersions without alpha-tocopherol, the loss of the carotenoid could be considered low. The thermal stresses of 75 and $95{ }^{\circ} \mathrm{C}$ are above the $\mathrm{T}_{\mathrm{PIT}}$ of the nanoparticles, which means the polar heads of the PEO surfactant were dehydrated, and although such dehydration could have altered the packing and permeability of the interface, the heat treatment did not seem to influence strong changes in average particle size or promote oxidation of beta-carotene.

Dehydration of PEO groups may also have occurred in the interface of lipid nanoparticles submitted to higher ionic strengths, as salts are capable of competing with polar groups for water molecules (Mei et al., 2011). However, as in the case of thermal stress, it the average particle size of the nanoparticles was not affected significantly, although the beta-carotene concentration decreased to a larger extent as the salt concentration increased, as shown in Table 2. These results support the hypothesis that the mechanical resistance of the tightly packed interface is not affected by the stress condition; instead, the high ionic strength appears to affect the permeability of the interface to oxidant species.

The results shown in Table 3 indicate sugar did not lead to any changes in mean particle size. However, higher sucrose concentrations seemed to favor degradation of the encapsulated betacarotene, which occurred to a lower extent in lipid nanoparticles containing alpha-tocopherol. This result indicates the essential role of the tocopherol in protecting the encapsulated carotenoid. Thanasukarn et al. (2006) found that the presence of sucrose in the aqueous phase increases short-range attraction between lipid particles via a mechanism similar to that of depletion flocculation. In the present case, even higher concentrations of sucrose did not penetrate the tightly packed surfactant layer covering the lipid nanoparticles and particle aggregation was avoided. However, while it could resist significant increases in average particle size, the stabilizing layer may undergo alterations in permeability, thereby facilitating the access of oxidant species to the encapsulated beta-carotene.

The results showing the high stability of the lipid nanoparticles in terms of both storage period and various stresses could be attributed to not only the reduced size of the particles but also the chemical composition of the cupuacu butter and surfactants used to stabilize the system. Cupuacu butter is rich in stearic and oleic acids, span 80 has an oleic acid chain in its structure, and Chremophor RH40 contains stearic acid chains. The similarity among the acyl chains of the surfactant and triglycerides of the lipid core of the particles presumably increased the interpenetration of the hydrophobic portion of the surfactant into the triglyceride chains. The higher the extent of interpenetration, the higher the probability of forming tightly packed interfaces, and therefore, the more resistant to destabilization the particles become (Tanaka et al., 2003).

\subsection{Evaluation of in vitro digestibility: comparison of static and dynamic in vitro methods}

Because of their higher physico-chemical stability, only lipid nanoparticles with alpha-tocopherol were used in further studies of in vitro digestibility. After the passing through the stomach in both static and dynamic systems, the mean average size of the particles was not significantly altered, as shown in Fig. 5; this result shows that the particles are resistant to severe acidic gastric conditions., and this characteristic is important because beta-carotene is absorbed in the small intestine. The zeta potential also increased significantly in the stomach step in both in vitro systems, likely because of changes in conditions of $\mathrm{pH}$ and ionic strength, as well as adsorption of charged species from the gastric electrolyte solution on the polar heads of surfactants (Hur et al., 2009).

The zeta potentials observed in both digestion systems after the duodenal step were very similar. The highly negative charge of the nanoparticles may results from displacement of the original surfactant by surface-active anionic molecules (e.g., free fatty acids, bile salts, or lipase), adsorption of anionic species at the nanoparticle surface, or adsorption of small negatively charged ions from the electrolyte solution of the small intestine (Tokle et al., 2012).

Discrepancies between the static and dynamic in vitro digestion 


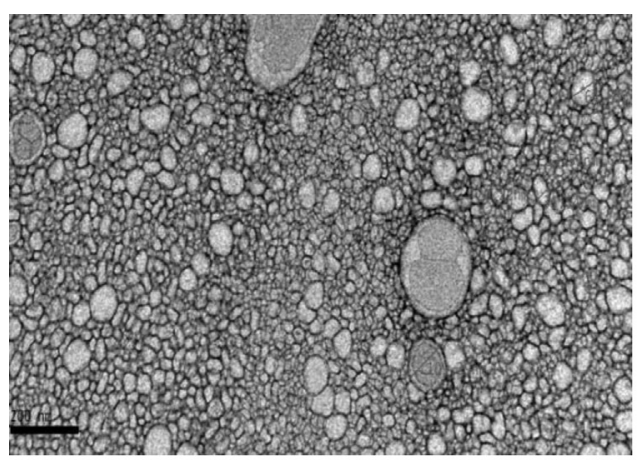

(A)

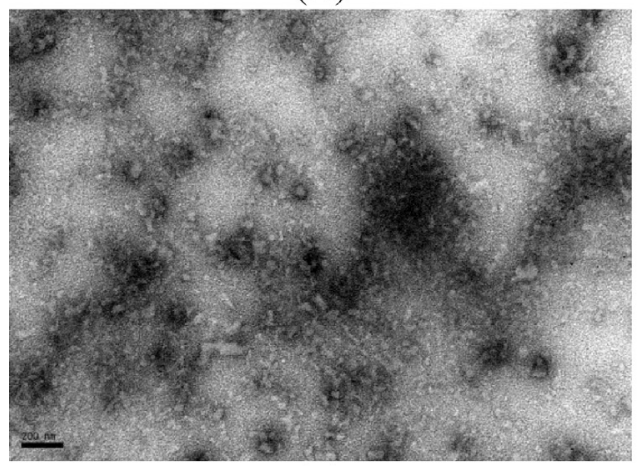

(C)

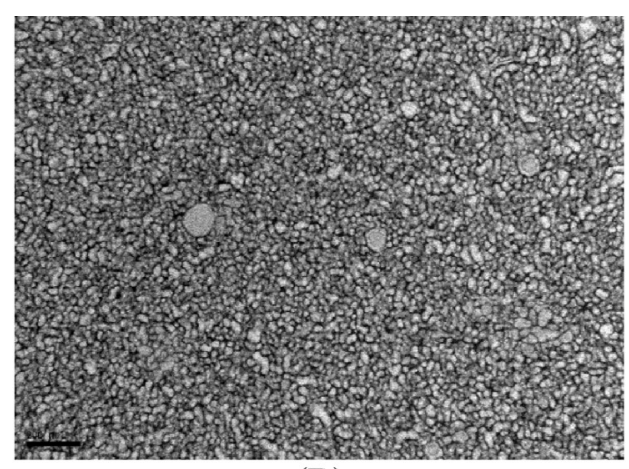

(B)

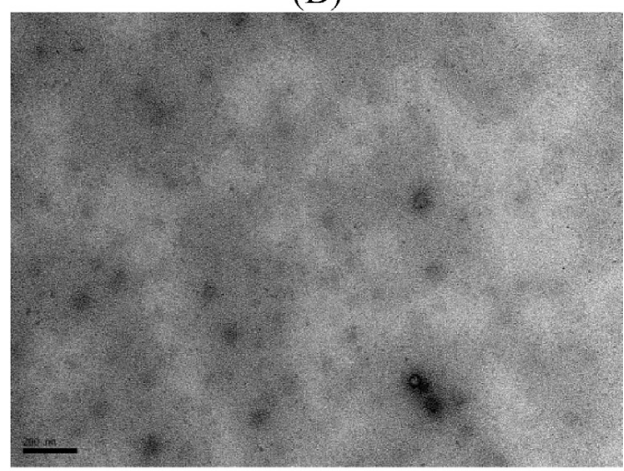

(D)

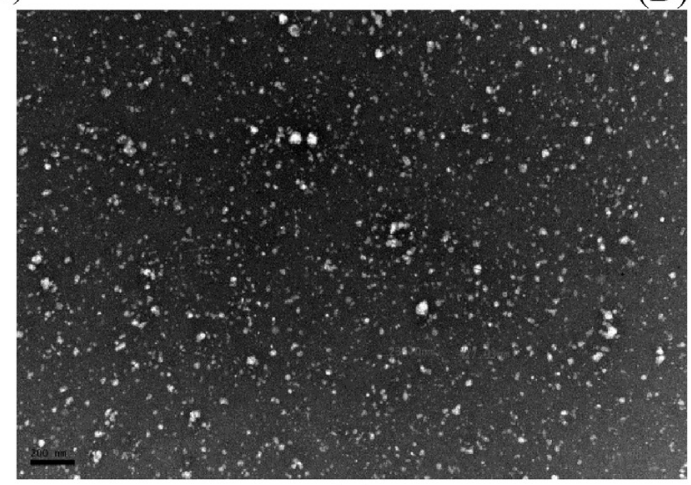

(E)

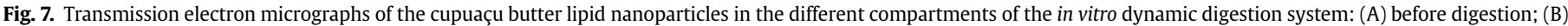
after stomach; (C) after duodenum; (D) after jejunum; (E) after ileum. (scale bar = $200 \mathrm{~nm}$ ).

approaches appeared when the particle size increased from $40 \mathrm{~nm}$ to $4000 \mathrm{~nm}$ in the static system but to only $92 \mathrm{~nm}$ in the dynamic system. This result is believed to be due to two important characteristics of the dynamic system that are not present in the static equipment:

(i) Injection of the simulated duodenal fluid along digestion, i.e., fluids are secreted over time and not all at once in the small intestine phase. Timed fluid injection prevents accumulation of excess enzymes and salts in the digestion environment, which could lead to higher levels of destabilization and flocculation of the nanoparticles; these phenomena occurred in the static system (Fig. 5(A)).

(ii) Simulation of peristaltic movements in the dynamic in vitro digestion system, necessary to reduce the size of the ingested food and helps prevent the extensive flocculation of particles after stomach.

The bioaccessibility of beta-carotene differed in the two systems. In the static system, as stated by Salvia-Trujillo et al (2013), bioaccessibility is calculated by taking the beta-carotene present in the raw digesta as the initial amount, not the betacarotene encapsulated in the nanoparticle sample before the stomach phase. Using this calculation methodology, 92.1\% bioaccessibility was obtained in the static system. This value is very high and similar to the results of Salvia-Trujillo et al. (2013), even though our nanoemulsions are very different from the nanoemulsions produced by the cited study.

The dynamic in vitro digestion system allows calculations of bioaccessibility after each intestinal step (i.e., duodenum, jejunum, and ileum), the results of which are shown in Fig. 6(A). The total bioaccessible beta-carotene, which was quantified by the carotenoid amount present in the jejunum and ileum filtrates, was 44.6\%. This value is significantly lower than that calculated by the methodology presented in several papers using static in vitro digestion systems, but it is certainly more reliable because the dynamic system used here was designed to include a more realistic scenario of the real phenomena occurring in the stomach and 
intestine during digestion.

The dynamic in vitro digestion system allowed observation that beta-carotene bioaccessibility tends to increase with digestion time (Fig. 6(A)). This behavior can be attributed to the formation of digestion products with the ability to produce mixed micelles capable of solubilizing highly lipophilic components, such as betacarotene. The relative amount of beta-carotene was also higher in the filtrate sample of the jejunal compartment compared with that in the ileal compartment at all times studied.

Fig. 6(B) shows the release of fatty acids after each compartment of intestinal digestion. The jejunum filtrate contained 31\% released fatty acids, $10 \%$ more than that found in the ileum filtrate. These results demonstrate that bioaccessibility and lypolysis are associated, i.e., the higher the amount of fatty acids released, the higher the micellization of beta-carotene in that compartment. A higher amount of fatty acids was released in the duodenal compartment (31.4\%) compared with that in the ileal compartment (20\%), in agreement with the higher beta-carotene micellization rate found in this step.

Fatty acid release could not be obtained in the static system because the digesta presented a dark color and titration could not be performed. This issue is a limitation of the static system.

Also, losses of beta-carotene along the dynamic in vitro digestion process, which was obtained by a mass balance, resulted in $11.8 \%$. Such a low value shows that the dynamic system is reliable in this aspect, as losses (e.g., residues adhered to the dynamic digestion model walls) can be considered low when the complexity of the process is taken into account.

Finally, Fig. 7 shows TEM micrographs of the dispersions after each digestion step in the dynamic system. The effects of digestion on the nanoparticles and their morphology are very clear, and the micrographs corroborate the data showing the degradation of betacarotene-loaded nanoparticles produced by the PIT method in this system.

\section{Conclusions}

Beta-carotene-loaded lipid nanoparticles were produced by the low-energy PIT method, and they presented excellent ability to protect encapsulated sensitive bioactives. Coencapsulation with alpha-tocopherol increased the ability of the nanoparticles to delay the degradation of beta-carotene for over 3 months of storage. A comparison of the digestibility and bioaccessibility of beta-carotene in static and dynamic in vitro digestion systems and the results obtained in both cases completely differed in terms of particle size and beta-carotene bioaccessibility. Of the two systems studied, the dynamic system yielded results more closely resembling actual observations. The dynamic in vitro digestion system appeared to be more reliable than the static system and allowed quantification of the amount of released fatty acids and bioaccessible beta-carotene in each intestinal compartment. Findings obtained from this system indicated a direct correspondence between fatty acid release and micellization of beta-carotene. These results reveal that the lipid nanoparticles produced in this study can potentially be used in the controlled release of bioactives.

\section{Acknowledgements}

The authors thank FAPESP (Fundação de Amparo à Pesquisa do Estado de São Paulo, Brazil) for the fellowships (grants 2010/205230, 2011/01260-0 and 2012/18495-3, authors Graziela V.L. Gomes and Mirella R. Sola). The author Ana C. Pinheiro is recipient of a fellowship from the Fundação para a Ciência e Tecnologia (FCT, Portugal) through grant SFRH/BPD/101181/2014.

\section{References}

Ahmed, K., Li, Y., McClements, D.J., Xiao, H., 2012. Nanoemulsion and emulsion based delivery systems for curcumin: encapsulation and release properties. Food Chem. 132, 799-807.

Anton, N., Benoit, J.P., Saulnier, P., 2008. Particular conductive behaviors of emulsion phase inverting. J. Drug Deliv. Sci. Technol. 18, 95-99.

Anton, N., Vandamme, T.F., 2009. The universality of low-energy nano-emulsification. Int. J. Pharm. 377, ,142-147.

Bonnaire, L.S., Helgason, T., Decker, E.A., Weiss, J., McClements, D.J., 2008. Influence of lipid physical state on the in vitro digestibility of emulsified lipids. J. Agric. Food Chem. 56, 3791-3797.

Bunjes, H., Unruh, T., 2007. Characterization of lipid nanoparticles by differential scanning calorimetry, X-ray and neutron scattering. Adv. Drug Deliv. Rev. 59, 379-402.

Cornacchia, L., Roos, Y.H., 2011a. Stability of $\beta$-carotene in protein-stabilized oil inwater delivery systems. J. Agric. Food Chem. 59, 7013-7020.

Cornacchia, L. Roos, Y.H., 2011b. State of dispersed lipid carrier and interface composition as determinants of beta-carotene stability in oil-in-water emulsions. J. Food Sci. 76, C1211-C1218.

Dias, M.I., Ferreira, I.C.F.R., Barreiro, M.F., 2015. Microencapsulation of bioactives for food applications. Food Funct. 6, 1035-1052.

Fernandez, P., Andre, V., Rieger, J., Kuhnle, A., 2004. Nano-emulsion formation by emulsion phase inversion. Colloids Surf. A Physicochem. Eng. Asp. 251, 53-58.

Gomes, G.V.L., Simplício, I.A.S., Cardoso, L.P., Souto, E., Pinho, S.C., 2013. Development of a lipid nanoparticle for beta-carotene encapsulation using a blend of tristearin and sunflower oil: choice of the lipid matrix and evaluation of the shelf life of dispersions. Food Technol. Biotechnol. 51, 383-391.

Hentschel, A., Gramdorf, S., Müller, R.H., Kurz, T., 2008. $\beta$-Carotene-loaded nanostructured lipid carriers. J. Food Sci. 73, 1-6.

Hur, S.J., Decker, E.A., McClements, D.J., 2009. Influence of initial emulsifier type on microstructural changes occurring in emulsified lipids during in vitro digestion. Food Chem. 114, 253-262.

Izquierdo, P., Esquena, J., Tadros, T.F., Dederen, J.C., Feng, J., Garcia-Celma, M.J., Azemar, N., Solans, C., 2004. Phase behavior and nano-emulsion formation by the phase inversion temperature method. Langmuir 20, 6594-6598.

Mehnert, W., Mäder, K., 2001. Solid lipid nanoparticles: production, characterization and applications. Adv. Drug Deliv. Rev. 47, 165-196.

McCallister, M., 2010. Dynamic dissolution: a step closer to predictive dissolution testing? Mol. Pharm. 7, 1374-1387.

McClements, D.J., Rao, J., 2011. Food-grade nanoemulsions: formulation, fabrication, properties, performance, biological fate, and potential toxicity. Crit. Rev. Food Sci. Nutr. 51, 285-330.

Mei, Z., Xu, J., Sun, D., 2011. O/W nano-emulsions with tunable PIT induced by inorganic salts nanoemulsion formation by phase inversion emulsification: on the nature of inversion. Colloids Surf. A Physicochem. Eng. Asp. 375, 102-108.

Montenegro, L., Campisi, A., Sarpietro, M.G., Carbone, C., Acquaviva, R., Raciti, G., Puglisi, G., 2011a. In vitro evaluation of idebenone-loaded solid lipid nanoparticles for drug delivery to the brain. Drug Dev. Ind. Pharm. 37, 737-746.

Montenegro, L., Sarpietro, M.G., Ottimo, S., Puglisi, G., Castelli, F., 2011b. Differential scanning calorimetry studies on sunscreen loaded solid lipid nanoparticles prepared by the phase inversion temperature method. Int. J. Pharm. 415, $301-306$.

Morales, D., Gutiérrez, J.M., García-Celma, M.J., Solans, C., 2003. A study of the relation between bicontinuous microemulsions and oil/water nano-emulsion formation. Langmuir 19, 7196-7200.

Müller, R.H., Mäder, K., Gohla, S., 2000. Solid lipid nanoparticles (SLN) for controlled drug delivery - a review of the state of the art. Eur. J. Pharm. Biopharm. 50, $161-177$.

Müller, R.H., Radtke, M., Wissing, S.A., 2002. Solid lipid nanoparticles (SLN) and nanostructured lipid carriers (NLC) in cosmetic and dermatological preparations. Adv. Drug Deliv. Rev. 54, S131-S155.

Pinheiro, A.C., Coimbra, M.A., Vicente, A.A., 2016. In vitro behaviour of curcumin nanoemulsions stabilized by biopolymer emulsifiers - effect of interfacial composition. Food Hydrocoll. 52, 460-467.

Pinheiro, A.C., Lad, M., Silva, H.D., Coimbra, M.A., Boland, M., Vicente, A.A., 2013. Unravelling the behaviour of curcumin nanoemulsions during in vitro digestion: effect of the surface charge. Soft Matter 9, 3147-3154.

Porter, C.J.H., Trevaskis, N.L., Charman, W.N., 2007. Lipids and lipid-based formulations: optimizing the oral delivery of lipophilic drugs. Nat. Rev. Drug Discov. 6, 231-248.

Qian, C., Decker, E.A., Xiao, H., McClements, D.J., 2012. Physical and chemical stability of $\beta$-carotene-enriched nanoemulsions: influence of $\mathrm{pH}$, ionic strength, temperature, and emulsifier type. Food Chem. 132, 1221-1229.

Reis, P.M., Raab, T.W., Chuat, J.Y., Leser, M.E., Miller, R., Watzke, H.J., Holmberg, K., 2008. Influence of surfactants on lipase fat digestion in a model gastrointestinal system. Food Biophys. 3, 370-381.

Relkin, P., Shukat, R., 2012. Food protein aggregates as vitamin-matrix carriers: impact of processing conditions. Food Chem. 134, 2141-2148.

Salvia-Trujillo, L., Qian, C., Martín-Belloso, O., McClements, D.J., 2013. Modulating beta-carotene bioaccessibility by controlling oil composition and concentration in edible nanoemulsions. Food Chem. 139, 878-884.

Solans, C., Solé, I., 2012. Nano-emulsions: formation by low-energy methods. Curr. Opin. Colloid Interface Sci. 17, 246-254. 
Solé, I., Maestro, A., Pey, C.M., González, C., Solans, C., Gutíerrez, J.M., 2006. Nanoemulsions preparation by low energy methods in an ionic surfactant system. Colloids Surf. A Physicochem. Eng. Asp. 288, 138-143.

Tan, C.P., Nakajima, M., 2005. $\beta$-Carotene nanodispersions: preparation, characterization and stability evaluation. Food Chem. 92, 661-671.

Tanaka, M., Saito, H., Arimoto, I., Nakano, M., Handa, T., 2003. Evidence for interpenetration of core triglycerides into surface phospholipid monolayers in lipid emulsions. Lagmuir 19, 5192-5196.

Thanasukarn, P., Pongsawatmanit, R., McClements, D.J., 2006. Impact of fat and water crystallization on the stability of hydrogenated palm oil-in-water emulsions stabilized by a nonionic surfactant. J. Agric. Food Chem. 54, 3591-3597.

Tikekar, R.V., Johnson, A., Nitin, N., 2011. Fluorescence imaging and spectroscopy for real-time, in-situ characterization of interactions of free radicals with oil-inwater emulsions. Food Res. Int. 44, 139-145.
Tikekar, R.V., Nitin, N., 2011. Effect of physical state (solid vs. liquid) of lipid core on the rate of transport of oxygen and free radicals in solid lipid nanoparticles and emulsion. Soft Matter 7, 8149-8157.

Tokle, T., Lesmes, U., Decker, E.A., McClements, D.J., 2012. Impact of dietary fiber coatings on behavior of protein-stabilized lipid droplets under simulated gastrointestinal conditions. Food Funct. 3, 58-66.

Weiss, J., Decker, E.A., McClements, D.J., Kristbergsson, K., Helgason, T., Awad, T., 2008. Solid lipid nanoparticles as delivery systems for bioactive food components. Food Biophys. 3, 146-154.

Wissing, S.A., Kayser, O., Muller, R.H., 2004. Solid lipid nanoparticles for parenteral drug delivery. Adv. Drug Deliv. Rev. 56, 1257-1272.

Wooster, T.J., Golding, M., Sanguansri, P., 2008. Impact of oil type on nanoemulsion formation and Ostwald ripening stability. Langmuir 24, 12758-12765. 